CARDIOVASCULAR MEDICINE

\title{
Infarct zone viability influences ventricular remodelling after late recanalisation of an occluded infarct related artery
}

\author{
N G Bellenger, Z Yousef, K Rajappan, M S Marber, D J Pennell
}

Heart 2005;91:478-483. doi: 10.1136/hrt.2004.034918

See end of article for authors' affiliations

Correspondence to:

Dr Nicholas G Bellenger,

Wessex Cardiothoracic

Unit, Southampton

General Hospital,

Southampton SO'16 6YD,

UK; nickbellenger@

doctors.org.uk

Accepted 24 May 2004

\begin{abstract}
Objective: To investigate the influence of infarct zone viability on remodelling after late recanalisation of an occluded infarct related artery.

Methods: A subgroup of 26 volunteers from TOAT (the open artery trial) underwent dobutamine stress cardiovascular magnetic resonance at baseline to assess the amount of viable myocardium present with follow up to assess remodelling at one year. TOAT studied patients with left ventricular dysfunction after anterior myocardial infarction (MI) associated with isolated proximal occlusion of the left anterior descending coronary artery with randomisation to percutaneous coronary intervention (PCI) with stent at 3.6 weeks after MI (PCl group) or to medical treatment alone (medical group).

Results: In the $\mathrm{PCl}$ group there was a significant relation between the number of viable segments within the infarct zone and improvement in end systolic volume index $\left(-7.7 \mathrm{ml} / \mathrm{m}^{2}, \mathrm{p}=0.02\right)$ and increased ejection fraction $(4.1 \%, p=0.03)$. The relation between viability and improvements in end diastolic volume index $\left(-8.8 \mathrm{ml} / \mathrm{m}^{2}, \mathrm{p}=0.08\right)$ and mass index $\left(-6.3 \mathrm{~g} / \mathrm{m}^{2}, \mathrm{p}=0.01\right)$ did not reach significance $(p=0.27$ and $p=0.8$, respectively). In the medical group, there was no significant relation between the number of viable segments in the infarct zone and the subsequent changes in end diastolic $(p=0.84)$ and end systolic volume indices $(p=0.34)$, ejection fraction $(p=0.1)$, and mass index $(p=0.24)$.

Conclusion: The extent of viable myocardium in the infarct zone is related to improvements in left ventricular remodelling in patients who undergo late recanalisation of an occluded infarct related artery.
\end{abstract}

$\mathrm{T}$ he presence of myocardial viability after acute myocardial infarction (MI) is important ${ }^{1-3}$ but little is known regarding the influence of viable myocardium on left ventricular (LV) remodelling in the setting of late recanalisation of the infarct related artery. The open artery hypothesis ${ }^{4}$ proposes that reperfusion of the infarct related artery improves prognosis ${ }^{5}$ by influencing myocardial salvage, ventricular remodelling, and electrical stability. ${ }^{67}$ While large clinical trials support early reperfusion, ${ }^{8-10}$ studies on the effects of late reperfusion (beyond the window for myocardial salvage) have yielded conflicting results. ${ }^{11}{ }^{12}$ None of these studies, however, investigated the role of viable myocardium within the infarct zone. We hypothesised that myocardial viability would influence the extent of LV remodelling after MI. We used dobutamine stress cardiovascular magnetic resonance (CMR) to assess myocardial viability in patients with anterior MI, LV dysfunction, and isolated proximal occlusion of the left anterior descending coronary artery (LAD), who underwent either late percutaneous coronary intervention (PCI) with stent to the LAD or medical treatment alone.

\section{METHODS \\ Patients}

For this pilot study, the patients were self selecting volunteers from TOAT (the open artery trial). ${ }^{13}$ Twenty six patients gave written informed consent. No patients were excluded for contraindications to CMR. The CMR study group therefore consisted of volunteers previously assigned randomly to PCI $(n=14)$ or medical treatment $(n=12)$ in the TOAT study. Randomisation is not by the degree of baseline viability. Criteria for enrolment in TOAT were presentation with an acute transmural anterior wall MI between March 1997 and June 1999, age < 75 years, an uncomplicated hospital course, sinus rhythm without bundle branch block, an early echocardiography derived ejection fraction $(\mathrm{EF})<50 \%$ or $\geqslant 3$ pathological Q waves in the precordial ECG leads, and a negative symptom limited modified Bruce protocol exercise test. The CMR study was approved by the hospitals' ethics committees.

\section{TOAT study protocol}

Details of the TOAT study have been previously published. ${ }^{14}$ Patients who fulfilled the enrolment criteria underwent coronary angiography between three and 28 days after MI. Patients with an occluded LAD (TIMI (thrombolysis in myocardial infarction) flow grade 0 or 1 ) and non-significant disease elsewhere $(<50 \%$ stenosis $)$ were randomly assigned to optimal medical treatment alone (medical group) or to PCI with a stent to the LAD together with optimal medical management (PCI group). PCI was performed either at the time of or within two weeks of angiography (overall between three days and six weeks of MI, mean 26 days). Angiographic success was defined as the restoration of TIMI grade 3 flow in the $\mathrm{LAD}$, together with $<50 \%$ residual vessel narrowing. One year after the index MI, all patients underwent repeat coronary angiography to redefine vessel patency. Medical management for all patients consisted of aspirin or clopidogrel, $\beta$ blockers, angiotensin converting enzyme inhibitors, and hydroxy-3-methylglutaryl coenzyme A reductase inhibitors (statins), as table 1 shows. Patients in the PCI group also

Abbreviations: $C M R$, cardiovascular magnetic resonance; $E D V$, end diastolic volume; $E D V_{1}$, end diastolic volume index; $E F$, ejection fraction; ESV, end systolic volume; ESV , end systolic volume index; LAD, left anterior descending coronary artery; $L V$, left ventricular; $M_{1}$, mass index; $\mathrm{Ml}$, myocardial infarction; $\mathrm{PCl}$, percutaneous coronary intervention; PTCA, percutaneous transluminal coronary angioplasty; SWIFT, should we intervene following thrombolysis?; TAMI-6, thrombolysis and angioplasty in myocardial infarction-6; TIMI, thrombolysis in myocardial infarction; TOAT, the open artery trial 
Table 1 Baseline characteristics of patients undergoing cardiovascular magnetic resonance

\begin{tabular}{|c|c|c|c|}
\hline & $\begin{array}{l}\text { Medical } \\
\text { group } \\
(n=11)\end{array}$ & $\begin{array}{l}\mathrm{PCl} \text { group } \\
(n=12)\end{array}$ & $\mathrm{p}$ Value \\
\hline Age (years) & $55.7(10.4)$ & $58.3(10.6)$ & 0.4 \\
\hline Men & $100 \%$ & $100 \%$ & \\
\hline Thrombolysis & $97 \%$ & $98 \%$ & 1.0 \\
\hline Peak creatine kinase (U/I) & 1800 & 2400 & 0.7 \\
\hline \multicolumn{4}{|l|}{ Risk factors } \\
\hline Diabetes & $27.3 \%$ & $30.8 \%$ & 0.6 \\
\hline Hypertension & $45.5 \%$ & $23.1 \%$ & $<0.001$ \\
\hline Dyslipidaemia & $27.3 \%$ & $30.8 \%$ & 0.6 \\
\hline Smoker at time of Ml & $36.4 \%$ & $46.2 \%$ & 0.2 \\
\hline \multicolumn{4}{|l|}{ Post-MI treatment } \\
\hline Aspirin & $100 \%$ & $100 \%$ & \\
\hline$\beta$ Blockers & $90.9 \%$ & $92.3 \%$ & 1.0 \\
\hline ACE inhibitors & $100 \%$ & $100 \%$ & \\
\hline Statins & $100 \%$ & $100 \%$ & \\
\hline \multicolumn{4}{|l|}{ Initial CMR } \\
\hline$E D V_{1}(\mathrm{ml})$ & $92(26)$ & $98(20)$ & 0.2 \\
\hline $\mathrm{ESV}_{1}(\mathrm{ml})$ & $53(27)$ & $58(24)$ & 0.5 \\
\hline Ejection fraction (\%) & 44 (14) & $43(14)$ & 0.8 \\
\hline $\operatorname{LVM}_{1}\left(\mathrm{~g} / \mathrm{m}^{2}\right)$ & $72(12)$ & $82(18)$ & 0.1 \\
\hline \multicolumn{4}{|l|}{ Screening angiogram } \\
\hline $\begin{array}{l}\text { Time from Ml to angiogram } \\
\text { (days) }\end{array}$ & $36.7(12.0)$ & $22.8(16.2)$ & 0.9 \\
\hline TIMI 0 flow & $63.6 \%$ & $91.7 \%$ & \\
\hline TIMI 1 flow & $36.4 \%$ & $8.3 \%$ & \\
\hline LVEDP $(\mathrm{mm} \mathrm{Hg})$ & 28.1 & 32.7 & 0.8 \\
\hline \multicolumn{4}{|c|}{$\begin{array}{l}\text { ACE, angiotensin converting enzyme; } E D V_{1} \text {, end diastolic volume index; } \\
\text { ESV, end systolic volume index; LVEDP, left ventricular end diastolic } \\
\text { pressure; LVM } \\
\text { TIMI, left ventricular mass index; MI, myocardial infarction; } \\
\text { insis in myocardial infarction. }\end{array}$} \\
\hline
\end{tabular}

received clopidogrel and higher dose aspirin for two weeks after the procedure.

\section{CMR}

Patients had CMR at a mean (SD) of 3.5 (2.9) weeks after randomisation ( 7.7 (2.6) weeks after MI). Of the 223 patients undergoing angiography, only 66 subsequently fulfilled the TOAT study angiographic criteria allowing entry to the main study, and only 23 patients volunteered for the viability study. Practical considerations therefore precluded baseline CMR of all patients before angiography. Because intervention was also sometimes performed at initial angiography (22 of 32 patients in TOAT and nine of 14 patients in the present subgroup), baseline CMR was performed shortly after angiography. Patients underwent a second scan 0.9 (0.1) year after randomisation ( 1 (0.1) year after MI).

CMR was performed with a Picker Edge $1.5 \mathrm{~T}$ scanner (Picker, Cleveland, Ohio, USA), with the body coil and ECG triggering as previously described. ${ }^{13}{ }^{15}$ In brief, a basal short axis cine was positioned just forward of the atrioventricular ring and contiguous breath-hold cines were acquired in $1 \mathrm{~cm}$ steps towards the apex. A breath-hold segmented gradient echo fast low angle shot sequence was used with the following parameters: echo time $3.8 \mathrm{~ms}$, repeat time equivalent to the RR interval, slice thickness $10 \mathrm{~mm}$, field of view $35 \times 35 \mathrm{~cm}$, read matrix 256, phase matrix 128, frames 16 , flip angle $35^{\circ}$, and phase encode group 6-10. After completion of the initial scans, dobutamine was infused at an initial rate of $5 \mu \mathrm{g} / \mathrm{kg} / \mathrm{min}$ followed by $10 \mu \mathrm{g} / \mathrm{kg} / \mathrm{min}$ after two minutes with imaging in the same planes as those at rest after a further five minutes. Patients were monitored with continuous ECG and blood pressure measurements. The same imaging parameters were used during dobutamine stress imaging but the ECG was reacquired and the number of phases adjusted to take into account any change in heart rate (fig 1). Two patients in each group did not wish to undergo dobutamine stress CMR at the time of their initial scan.
Images were analysed on a personal computer with inhouse developed software (CMRtools, Imperial College). End diastolic and end systolic images were chosen as the maximum and minimum cross sectional areas in each cine. End diastolic epicardial and endocardial borders were traced manually for each slice. From the area within the contours and the slice thickness, the epicardial and end diastolic (EDV) endocardial volumes were calculated, the difference being the myocardial volume. Mass was derived from this volume by multiplying by the specific density of myocardium $\left(1.05 \mathrm{~g} / \mathrm{cm}^{3}\right) .{ }^{16}$ End systolic endocardial borders were also traced for end systolic volume (ESV); the difference between EDV and ESV is the LV stroke volume. EF was calculated as LV stroke volume divided by EDV. Papillary muscles were included in the mass and excluded from the volume. Since coronary stents are visible with CMR, fully blinded analysis was not possible and therefore all analyses were anonymised and presented in random order, with investigators blinded to the patient details and previous results. Wall motion was assessed in a 16 segment model. ${ }^{17-19}$ Regional wall motion was graded visually and segments were assigned a wall motion score, where 0 indicates not assessable, 1 is normal, 2 is hypokinetic, 3 is akinetic, and 4 is dyskinetic. For each segment, viable myocardium was considered to be present if there was normal wall motion at rest or if dysfunctional segments improved by at least one full grade during dobutamine stress. Furthermore, for myocardium to be defined as viable, the end diastolic wall thickness of each segment had to be $>5.5 \mathrm{~mm}$ and the dobutamine induced systolic wall thickening had to be $>2 \mathrm{~mm} \cdot{ }^{17-19}$ Thus, viability incorporated both wall motion and wall thickening. The infarct zone was defined by the segments that displayed abnormal wall motion at baseline. The number of these infarct zone segments that displayed viability was also recorded.

\section{Statistical analysis}

To control for changes in body mass over the study period, LV EDV, ESV, and mass were expressed as an index of total body mass (end diastolic volume index $\left(\mathrm{EDV}_{\mathrm{I}}\right)$, end systolic volume index $\left(\mathrm{ESV}_{\mathrm{I}}\right)$, and mass index $\left.\left(\mathrm{M}_{\mathrm{I}}\right)\right)$. Differences between groups were assessed by an unpaired $t$ test. Results are expressed as mean (SD) with $\mathrm{p}<0.05$ being considered significant. Differences in clinical variables between the initial scan and after one year within the PCI and medical groups were assessed by a paired $t$ test. Multivariate logistic regression analysis was performed to assess the relation between continuous independent variables of haemodynamic function and remodelling over the study period and to assess the influence of the number of viable segments on the changes in each group. Analysis of variance was performed to assess the relation between nominal independent variables (risk factors and individual medications) and these continuous independent variables. Two way analysis of variance was performed to assess the volume, mass, and functional differences between groups both at baseline and at follow up. Wall motion score and number of viable segments in each group were compared by a non-parametric unpaired Wilcoxon test (Mann-Whitney test). These data are not normally distributed and so the mean rank and not the mean is quoted. Data were analysed by commercial software (StatView version 4.53; Abacus Concepts, Berkeley, California, USA). The reproducibility of CMR in our centre is $2.5 \%$ for EDV, $3.1 \%$ for ESV, $4.8 \%$ for $\mathrm{EF}$, and $3 \%$ for $\mathrm{LV}$ mass (thus, about half these values for equivalent $\mathrm{EDV}_{\mathrm{I}}$, $\mathrm{ESV}_{\mathrm{I}}$, and $\mathrm{M}_{\mathrm{I}}$ assuming a body mass index of $\left.2 \mathrm{~m}^{2}\right) . .^{13}{ }^{15}$

\section{RESULTS}

Table 1 shows the baseline characteristics of the 26 patients enrolled in the CMR viability study. The only significant 


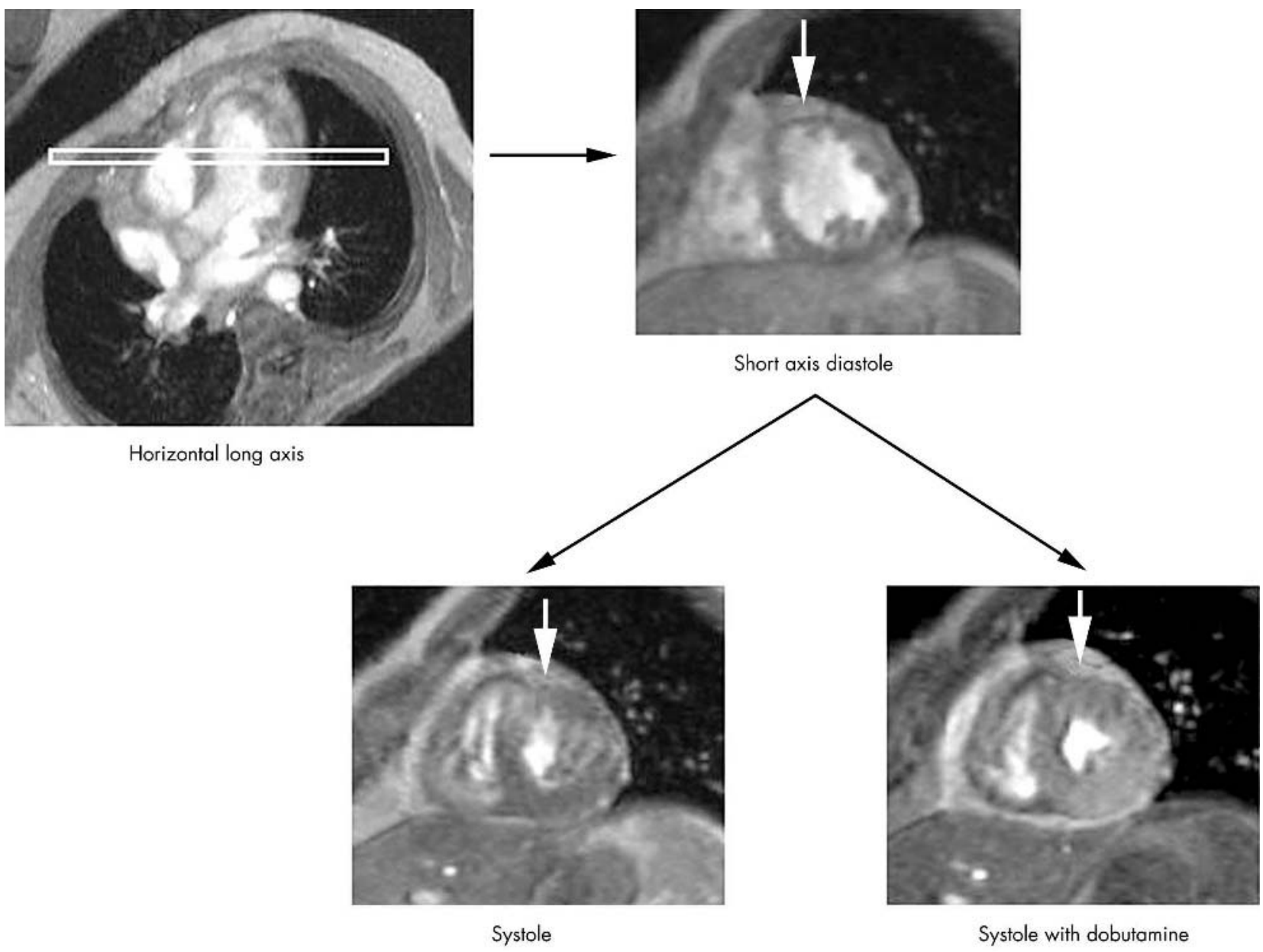

Figure 1 Cardiovascular magnetic resonance short axis images in diastole and systole. White arrows point to a viable segment with increased wall motion and thickening in systole during the administration of dobutamine.

difference between the two groups was a higher history of hypertension in the medical group $(\mathrm{p}<0.001)$; however, there was no difference in LV mass between groups. Four patients failed to attend the follow up CMR scan: two from the PCI group (one patient underwent bypass surgery and aneurysmectomy during follow up, one declined follow up) and two in the medical group (patient refusal).

\section{Influence of viability on remodelling}

There were no significant baseline differences between the PCI and medical groups in LV volumes and mass. LV volumes and EF were outside the CMR normal range. ${ }^{20}$ At the initial CMR, both groups had equivalent MI sizes according to the total resting wall motion scores (PCI group mean rank 12, medical group mean rank 10, p = 0.3) and the number of viable segments present (PCI group 12 segments, medical group 10 segments, $\mathrm{p}=0.14)$. The total resting wall motion score and the number of infarcted (abnormal baseline wall motion) or normal segments at baseline were not significantly associated with subsequent changes in $\mathrm{EDV}_{\mathrm{I}}, \mathrm{ESV}_{\mathrm{I}}, \mathrm{EF}$, or $\mathrm{M}_{\mathrm{I}}$ in either the PCI or the medical group.

In the PCI group there was a significant relation between the number of viable segments within the infarct zone and improvement in $\operatorname{ESV}_{\mathrm{I}}(\mathrm{p}=0.01)$, which decreased significantly over one year $\left(-7.7 \mathrm{ml} / \mathrm{m}^{2}, \mathrm{p}=0.02\right)$, as well as improvement in EF $(\mathrm{p}=0.05)$, which increased significantly $(4.1 \%, \mathrm{p}=0.03)$. The changes in $\operatorname{EDV}_{\mathrm{I}}(-8.8 \mathrm{ml} /$ $\left.\mathrm{m}^{2}, \mathrm{p}=0.08\right)$ and $\mathrm{M}_{\mathrm{I}}\left(-6.3 \mathrm{~g} / \mathrm{m}^{2}, \mathrm{p}=0.01\right)$ were not significantly associated with the number of viable segments present $(\mathrm{p}=0.27$ and $\mathrm{p}=0.8$, respectively).

In the medical group, there was no significant relation between the number of viable segments in the infarct zone at the time of the initial CMR scanning and the subsequent changes in $\operatorname{EDV}_{I}(p=0.84), \operatorname{ESV}_{I}(p=0.34), \quad E F$ $(p=0.1)$, and $M_{I}(p=0.24)$. In the medical group, there were no significant changes in $\operatorname{EDV}_{I}(p=0.32), \operatorname{ESV}_{I}$ $(p=0.62), E F(p=0.46)$, and $M_{I}(p=0.43)$ at one year's follow up.

\section{Influence of clinical variables on remodelling}

None of the baseline characteristics of age, heart rate, systolic blood pressure, peak creatine kinase rise, presence or absence of conventional risk factors, treatment with $\beta$ blockade or angiotensin converting enzyme inhibitors, early post-MI LV volumes, or angiographic stenotic scores (by quantitative coronary angiography) were significantly associated with the degree of changes in ventricular volume and mass parameters over one year.

\section{DISCUSSION}

This is the first pilot study to examine directly the influence of viable myocardium on remodelling in a prospective randomised trial comparing late PCI with medical treatment in patients remaining symptom-free after MI. The main finding of this study is that the extent of viable myocardium in the infarct zone is related to the extent of improvement in 
LV remodelling after late recanalisation of an occluded infarct related artery, compared with no such changes in the medical group.

\section{Previous studies of late opening of the infarct related artery}

The beneficial effects of early opening of an occluded infarct related artery are established but the value of opening of an occluded infarct related artery in the chronic phase has been controversial. ${ }^{14} 21$ In the TAMI-6 (thrombolysis and angioplasty in myocardial infarction-6) study, ${ }^{22} 71$ patients with occluded infarct related arteries were randomly assigned to PCI or medical treatment 24 hours after failed thrombolysis. There was improvement in LV function at one month but no benefit by six months. This study, however, had a number of limitations, most notably, a considerable restenosis rate in the PCI group together with failed angiographic follow up of $50 \%$ of patients. Similarly, in the TIMI $\mathrm{II}^{23}$ and SWIFT (should we intervene following thrombolysis?) studies, ${ }^{24}$ no improved clinical outcome was seen comparing delayed elective PCI with medical treatment. In contrast, Dzavik et al ${ }^{25}$ found improved EF after late opening of the infarct related artery compared with conservative treatment. Pizzetti et al ${ }^{26}$ also described improved LV function in 16 patients who underwent PCI at 18 days after MI. Pfisterer et al studied 16 patients randomly assigned to immediate (two weeks) or delayed (three months) PCI, showing superior benefit for the two week intervention due to improved regional infarct wall motion and decreased ESV. Similarly, Horie et al found that late PCI was associated with a significant decrease in EDV and ESV and an increased event-free survival over five years compared with no PCI. Although it has been postulated that the improvement in LV function was due to the residual viable myocardium, no study has previously measured the degree of myocardial viability present.

\section{Evidence for the role of viability}

Early studies suggested that preserved blood flow in the infarct zone independent of myocardial salvage cannot prevent remodelling when the necrosis is extensive. ${ }^{27}$ Later studies, however, pointed out that for a comparable infarct size the transmural extent of necrosis was the major determinant of later infarct expansion..$^{28-30}$ In animal and postmortem studies the extent of infarct expansion was inversely related to the thickness of the surviving myocardium or more specifically the preservation of small islets of viable myocytes located mainly in the subepicardium of the scar. ${ }^{31}{ }^{32}$ Authors have suggested that the presence of viable myocardium in the outer layers of the ventricular wall contributes to the maintenance of LV shape and size by preventing infarct expansion. ${ }^{33}$ Bolognese et $a l^{34}$ confirmed these experimental observations that residual myocardial viability in the infarct zone is an important contributor to later LV remodelling. In a study of 93 patients after anterior and inferior MI, all of whom had successful early percutaneous transluminal coronary angioplasty (PTCA) (within six hours) and dobutamine stress echocardiography viability analysis, an inverse linear relation was found between LV $\mathrm{EDV}_{\mathrm{I}}$ change over six months and infarct zone viability and suggested that preserved flow to the infarct zone cannot prevent remodelling when infarct zone viability is absent. This study, however, was of early opening of the occluded infarct related artery and did not enrol any patients who did not undergo PTCA. Using a different technique, Ito $e t$ al $^{35}$ also found that microvascular integrity in the infarct zone, a sensitive marker of viability, prevents LV remodelling in reperfused patients. Although not randomised, a trial by Faraggi $e t a l^{36}$ used rest redistribution thallium as a measure of viability to study the relation between angiographic patency of the infarct related artery and subsequent LV improvement over six months in 52 patients recruited three weeks after anterior MI. They found that myocardial viability persisted for a long time, even with an occluded infarct related artery, but preserved anterograde flow was required to improve LV function. More recent animal and human studies with dobutamine stress CMR have also suggested that the degree of viable myocardium after MI directly influences reverse remodelling. ${ }^{37}$ Our results are consistent with these studies, although none of these groups specifically addressed the issue of the influence of viable myocardium in the setting of late PCI after MI and none attempted to assign patients randomly to PCI and medical treatment arms.

\section{Possible mechanisms of benefit from late PTCA}

The benefit exerted on remodelling by late opening of an occluded infarct related artery is likely to be multifactorial. It has been suggested that reperfusion causes haemorrhage, contraction band necrosis, cell swelling, oedema, and promotion of the healing process, all of which may serve to strengthen the infarct area and limit both initial expansion and later dilatation. ${ }^{38}$ The data presented here, however, suggest not only that adverse remodelling is prevented by opening of the infarct related artery but also that active reverse remodelling occurs with a decrease in the LV volumes and subsequent improved global function after restoration of blood flow to viable myocardium. The key may, therefore, be the interaction between viable myocardium (areas with contractile reserve at low dose dobutamine) and the ischaemic burden of that viable tissue. Coletta et al ${ }^{39}$ showed that viable myocardium within the infarct zone (contractile reserve at low dose dobutamine at eight days after anterior MI) obviates LV remodelling. In contrast, an ischaemic response at high dose dobutamine (biphasic response) was strongly related to subsequent remodelling and, in a second study, to prognosis.$^{40}$ These studies did not, however, provide angiographic data or control for coronary intervention. More recently, Rizzello et $a l^{41}$ found that after revascularisation of ischaemic cardiomyopathy, functional recovery occurred only in those segments with viable myocardium (at low dose dobutamine) and the additional ischaemic biphasic response at high dose dobutamine. Areas without ischaemia consisted of subendocardial scar that failed to improve after revascularisation. Our study did not use high dose dobutamine to control specifically for myocardial ischaemia but it did control for the presence of flow in the infarct related artery. Such interaction between viability and blood flow may relate, in part, to myocardiocyte loss through apoptosis. ${ }^{42}$ A link between coronary artery occlusion and apoptosis even late after MI has been suggested by animal models where a persistently increased apoptosis rate at the border zone of infarction was observed up to 12 weeks after MI with subsequent adverse LV remodelling. ${ }^{43}$ Other animal studies have shown that although reperfusion after MI accelerates apoptosis in the non-salvageable myocardiocytes, there are significantly fewer cells undergoing apoptosis. ${ }^{44}$ Furthermore, Abbate $a t ~ a l^{45}$ assessed the influence of infarct related artery status on apoptotic rate in the hearts of patients dying late after MI. They confirmed that apoptosis persists beyond the acute phase of MI and found a significantly higher apoptotic rate in patients with persistent infarct related artery occlusion. Others have investigated the adverse effect of chronic sympathetic denervation and $\beta$ receptor downregulation on remodelling. ${ }^{46} \beta$ Receptor density can decrease in remote non-infarcted myocardium, and a patent infarct related artery appears to be associated with a higher $\beta$ receptor density in non-infarcted myocardium, with subsequent beneficial remodelling. ${ }^{47}$ 
The exact mechanism of benefit from late PTCA has yet to be determined, but this study provides further evidence of an important interaction between viable myocardium and a patent infarct related artery. Further investigation may be aided by new delayed enhancement CMR techniques that allow direct visualisation of post-MI scar tissue and viable myocardium.

\section{Study limitations}

The conclusions of this pilot study are limited by the small sample size. The high reproducibility of CMR enables differentiation of structural and functional changes in small sample sizes, but the use of small samples may not adequately control for confounding variables. Nevertheless, this pilot study makes use of a highly reproducible technique to investigate patients in a prospective randomised trial and as such lends considerable weight to the hypothesis that viability may play a significant part in the open artery hypothesis. This insight should provide justification for a larger randomised study. Such a study could now include contrast enhanced CMR techniques and quantitative analysis of wall motion score, which were unavailable at the time of the present study. The semiquantitative wall motion scoring used in this study, however, has previously been shown to assess viability accurately. ${ }^{17}$ It was disappointing that not all patients could attend follow up CMR, a reflection of the limited availability of CMR and the distance patients were consequently required to travel. The two groups in this study were well matched but by chance there was a significantly higher history of hypertension in the medical group (although no difference in LV mass between groups). It is conceivable that, despite the similar LV masses, previous hypertension may affect subsequent remodelling. Such remodelling may be adverse but may also be beneficial, particularly in the presence of medical treatment with angiotensin converting enzyme inhibitors and $\beta$ blockers. The small sample size of this pilot study does not allow for strict control for this potential confounder or for subgroup analysis.

TOAT showed no significant change in LV volumes by echocardiography ( $\mathrm{n}=66$ ) over one year in the closed artery group but, in contrast to this study, ESV and EDV increased significantly in the open artery group. These differences may reflect different patient characteristics in the CMR subgroup. For example, the CMR group was formed of patients volunteering to participate in an additional clinical study, and comparison of the CMR group with TOAT patients showed that the CMR patients were healthier, had better exercise endurance, had better quality of life assessment scores, and had fewer clinical events over the year. The conclusion from TOAT was that taking all comers, late recanalisation of an infarct related artery does not lead to improvement in LV remodelling. This CMR viability pilot study examined this concept further and showed that a subgroup of patients who retain viable myocardium may undergo reverse remodelling after late recanalisation of an infarct related artery, with the degree of benefit directly related to the amount of viable myocardium present in the infarct zone.

\section{Conclusion}

The extent of viable myocardium in the infarct zone is related to improvements in LV remodelling in patients who undergo late recanalisation of an occluded infarct related artery. A larger study should assess whether significant improvements in LV function may be predicted in patients undergoing late coronary intervention by early assessment of residual myocardial viability.

\section{ACKNOWLEDGEMENTS}

Dr Yousef and Professor Marber were supported in part by the British Heart Foundation (BHF PG 97051). Dr Bellenger was supported by an unrestricted grant from SmithKline Beecham. Support for this work was also received from CORDA and the Welcome Trust. We are grateful to Jane Francis for her assistance.

\section{Authors' affiliations}

N G Bellenger, K Rajappan, D J Pennell, Cardiovascular MR Unit, Royal Brompton Hospital, National Heart and Lung Institute, Imperial College, London, UK

Z Yousef, M S Marber, Department of Cardiology, Kings College London, The Rayne Institute, Guy's and St Thomas' Hospital, London, UK

\section{REFERENCES}

1 Carlos ME, Smart SC, Wynsen JC, et al. Dobutamine stress echocardiography for risk stratification after myocardial infarction. Circulation 1997; 95:1402-10.

2 Bolognese L, Cerisano G, Buonamici P, et al. Influence of infarct-zone viability on left ventricular remodeling after acute myocardial infarction. Circulation 1997:96:3353-9.

3 Geskin G, Kramer CM, Rogers WJ, et al. Quantitative assessment of myocardial viability after infarction by dobutamine magnetic resonance tagging. Circulation 1998;98:217-23.

4 Braunwald $\mathbf{E}$. The open-artery theory is alive and well again. N Engl J Med 1993:329:1650-2.

5 White HD, Cross DB, Elliott JM, et al. Long-term prognostic importance of patency of the infarct-related coronary artery after thrombolytic therapy for acute myocardial infarction. Circulation 1994;89:61-7.

6 Braunwald E. Myocardial reperfusion, limitation of infarct size, reduction of left ventricular dysfunction, and improved survival: should the paradigm be expanded? Circulation 1989;79:441-4.

7 Mortara A, Specchia G, La Rovere MT, et al. Patency of infarct related artery: effect of restoration of anterograde flow on vagal reflexes. Circulation 1996:93:1114-22.

8 TIMI Study Group. The thrombolysis in myocardial infarction (TIMI) trial: phase I findings. The TIMl study group. N EnglJ Med 2000;312:932-6.

9 GUSTO Investigators. An international randomized trial comparing four thrombolytic strategies for acute myocardial infarction. The GUSTO investigators. N Engl J Med 1993;329:673-82.

10 GUSTO Angiographic Investigators. The effects of tissue plasminogen activator, streptokinase, or both on coronary artery patency, ventricular function, and survival after myocardial infarction. The GUSTO angiographic investigators. N Engl J Med 1993;329:1615-22.

11 Kim CB, Braunwald E. Potential benefits of late reperfusion of infarcted myocardium. Circulation 1993;88:2426-36.

12 Horie H, Takahashi M, Minai K, et al. Long-term beneficial effect of late reperfusion for acute anterior myocardial infarction with percutaneous transluminal coronary angioplasty. Circulation 1998;98:2377-82.

13 Bellenger NG, Francis JM, Davies LC, et al. Establishment and performance of a magnetic resonance cardiac function clinic. J Cardiovasc Magn Reson 2000;2:15-22

14 Yousef RY, Redwood SR, Bucknall CA, et al. Late angioplasty after anterior myocardial infarction: effects on left ventricular size and function, quality of life, and exercise tolerance: results of the open artery trial (TOAT study). J Am Coll Cardiol, (in press).

15 Bellenger NG, Davies LC, Francis JM, et al. Reduction in sample size for studies of remodelling in heart failure by the use of cardiovascular magnetic resonance. J Cardiovasc Magn Reson 2000;2:271-8.

16 Katz J, Milliken MC, Stray-Gundersen J, et al. Estimation of human myocardial mass with MR imaging. Radiology 1988;169:495-8.

17 Baer FM, Voth E, Schneider CA, et al. Comparison of low dose dobutamine gradient echo magnetic resonance imaging and positron emission tomography with ${ }^{8} \mathrm{~F}$ in patients with chronic coronary artery disease. Circulation 1995;91:1006-15.

18 Baer FM, Voth E, LaRosee K, et al. Comparison of dobutamine transesophageal echocardiography and dobutamine magnetic resonance imaging for detection of residual myocardial viability. Am J Cardiol 1996;78:415-9.

19 Dendale PA, Franken PR, Waldman GJ, et al. Low-dosage dobutamine magnetic resonance imaging as an alternative to echocardiography in the detection of viable myocardium after acute infarction. Am Heart $J$ 1995; 130:134-40.

20 Lorenz CH, Walker ES, Morgan VL, et al. Normal human right and left ventricular mass, systolic function and gender differences by cine magnetic resonance imaging. J Cardiovasc Magn Reson 1999;1:7-21.

21 Sadanandan S, Buller C, Menon V, et al. The late open artery hypothesis: a decade later. Am Heart J 2001;142:411-21.

22 Topol EJ, Califf RM, Vandormael M, et al. A randomized trial of late reperfusion therapy for acute myocardial infarction. Thrombolysis and angioplasty in myocardial infarction- 6 study group. Circulation 1992:85:2090-9.

23 Williams DO, Braunwald E, Knatterud G, et al. One-year results of the thrombolysis in myocardial infarction investigation (TIMI) phase II trial. Circulation 1992;85:533-42. 
24 SWIFT Study Group. SWIFT (should we intervene following thrombolysis?) trial study group. BMJ 1991;302:555-60.

25 Dzavik V, Beanlands DS, Davies RF, et al. Effects of late percutaneous transluminal coronary angioplasty of an occluded infarct related coronary artery on left ventricular function in patients with a recent ( $<6$ weeks) $Q$-wave acute myocardial infarction (total occlusion post-myocardial infarction intervention study (TOMIIS): a pilot study). Am J Cardiol 1994;73:856-61.

26 Pizzetti G, Belotti G, Margonato A, et al. Coronary recanalization by elective angioplasty prevents ventricular dilation after anterior myocardial infarction. J Am Coll Cardiol 1996:28:837-45.

27 Chareonthaitawee P, Christian TF, Hirose K, et al. Relation of initial infarct size to extent of left ventricular remodelling in the year after acute myocardial infarction. J Am Coll Cardiol 1995;25:567-73.

28 Eaton LW, Weiss JL, Bulkley BH, et al. Regional cardiac dilatation after acute myocardial infarction: recognition by two-dimensional echocardiography. N Engl J Med 1979;300:57-62.

29 Pirolo JS, Hutchins GM, Moore GW. Infarct expansion: pathologic analysis of 204 patients with a single myocardial infarct. J Am Coll Cardiol 1986:7:349-54.

30 Jugdutt BL. Nitrates and left ventricular remodelling. Am J Cardiol 1998;81:57A-67A

31 Pirolo JS, Hutchins GM, Moore GW. Infarct expansion: pathologic analysis of 204 patients with a single myocardial infarct. J Am Coll Cardiol 1986:7:349-54.

32 Alhaddad IA, Kloner RA, Hakim I, et al. Benefits of late coronary reperfusion on infarct expansion progressively diminish over time: relation to viable islets of myocytes within the scar. Am Heart J 1996;131:451-7.

$33 \mathrm{Kaul} \mathrm{S}$. There may be more to myocardial viability than meets the eye. Circulation 1995:92:2790-3.

34 Bolognese L, Cerisano G, Buonamici P, et al. Influence of infarct-zone viability on left ventricular remodeling after acute myocardial infarction. Circulation 1997; 96:3353-9

35 Ito H, Maruyama A, Iwakura K, et al. Clinical implications of the "no reflow" phenomenon: a predictor of complications and left ventricular remodeling in reperfused anterior wall myocardial infarction. Circulation 1996;93:223-8.

36 Faraggi M, Montalescot G, Sarda L, et al. Spontaneous late improvement of myocardial viability in the chronic infarct zone is possible, depending on persistent TIMI 3 flow and a low grade stenosis of the infarct artery. Heart 1999;81:424-30

37 Rogers WJ, Kramer CM, Geskin G, et al. Early contrast-enhanced MRI predicts late functional recovery after reperfused myocardial infarction. Circulation 1999:99:744-50.

$38 \mathrm{Kim}$ CB, Braunwald E. Potential benefits of late reperfusion of infarcted myocardium. Circulation 1993;88:2426-36.

39 Coletta C Sestili A, Seccareccia F, et al. Influence of contractile reserve and inducible ischaemia on left ventricular remodelling after acute myocardial infarction. Heart 2003;89:1138-43.

40 Bigi R, Desideri A, Bax JJ, et al. Prognostic interaction between viability and residual myocardial ischaemia by dobutamine stress echo in patients with acute $\mathrm{MI}$ and mildly impaired left ventricular function. Am J Cardiol $2001 ; 87: 283-8$.

41 Rizzello V, Biagini E, Schinkel AFL, et al. Comparison of functional recovery of mildly hyopkinetic versus severely dysfunctional left ventricular segments after revascularization in patients with ischaemic cardiomyopathy. Am J Cardiol 2004;93:394-8.

42 Abbate A, Biondi-Zoccai GG, Baldi A. Pathophysiologic role of myocardial apoptosis in post-infarction left ventricular remodelling. J Cell Physiol 2002; 193:145-53.

43 Palojoki E, Saraste A, Erickson A, et al. Cardiomyocyte apoptosis and ventricular remodelling after myocardial infarction in rats. Am J Physiol 2001;280: $\mathrm{H} 2726-30$

44 Fliss H, Gattinger D. Apoptosis in ischaemic and reperfused rat myocardium. Circ Res 1996;79:949-56.

45 Abbate A, Bussani R, Biondi-Zoccai GC, et al. Persistent infarct-related artery occlusion is associated with an increased myocardial apoptosis at postmortem examination in humans late after an acute myocardial infarction. Circulation 2002; 106:1051-4

46 Kramer CM, Nicol PD, Rogers WJ. Reduced sympathetic innervation underlies adjacent noninfarcted region dysfunction during left ventricular remodeling. J Am Coll Cardiol 1997:30:1079-85.

47 Spyrou N, Rosen SD, Fath-Ordoubadi F, et al. Myocardial beta-adrenoceptor density one month after acute myocardial infarction predicts left ventricular volumes at six months. J Am Coll Cardiol 2002;40:1216-24.

\section{IMAGES IN CARDIOLOGY}

\section{Stenting of left main stem thrombosis}

A

41 year old male hypertensive smoker presented with acute abdominal pain and transient widespread ST elevation on the ECG. Coronary angiography (panel A) revealed a mobile opacity in the proximal left main stem (arrow) and a slow flow phenomenon in the left anterior descending artery. Treatment was given with aspirin, clopidogrel, low molecular weight heparin and a tirofiban infusion over three days. Repeat angiography showed identical appearances in the left main stem with normal flow in the left anterior descending artery. Intravascular ultrasound of the left main stem (panel B) showed a non-occlusive atherosclerotic plaque (X) with adherent thrombus (Y). An attempt to aspirate the thrombus using the Rescue thrombosis management system failed. The lesion was therefore treated with stenting using a $4.5 \times 13 \mathrm{~mm}$ Ultra bare metal stent, postdilated to $5 \mathrm{~mm}$ (panels $\mathrm{C}$ and $\mathrm{D}$ ). The patient made an uneventful recovery. Repeat angiography is planned at four months.

\section{J H McGowan \\ D A Begley \\ A G C Sutton \\ jamesmcgowan@doctors.org.uk}
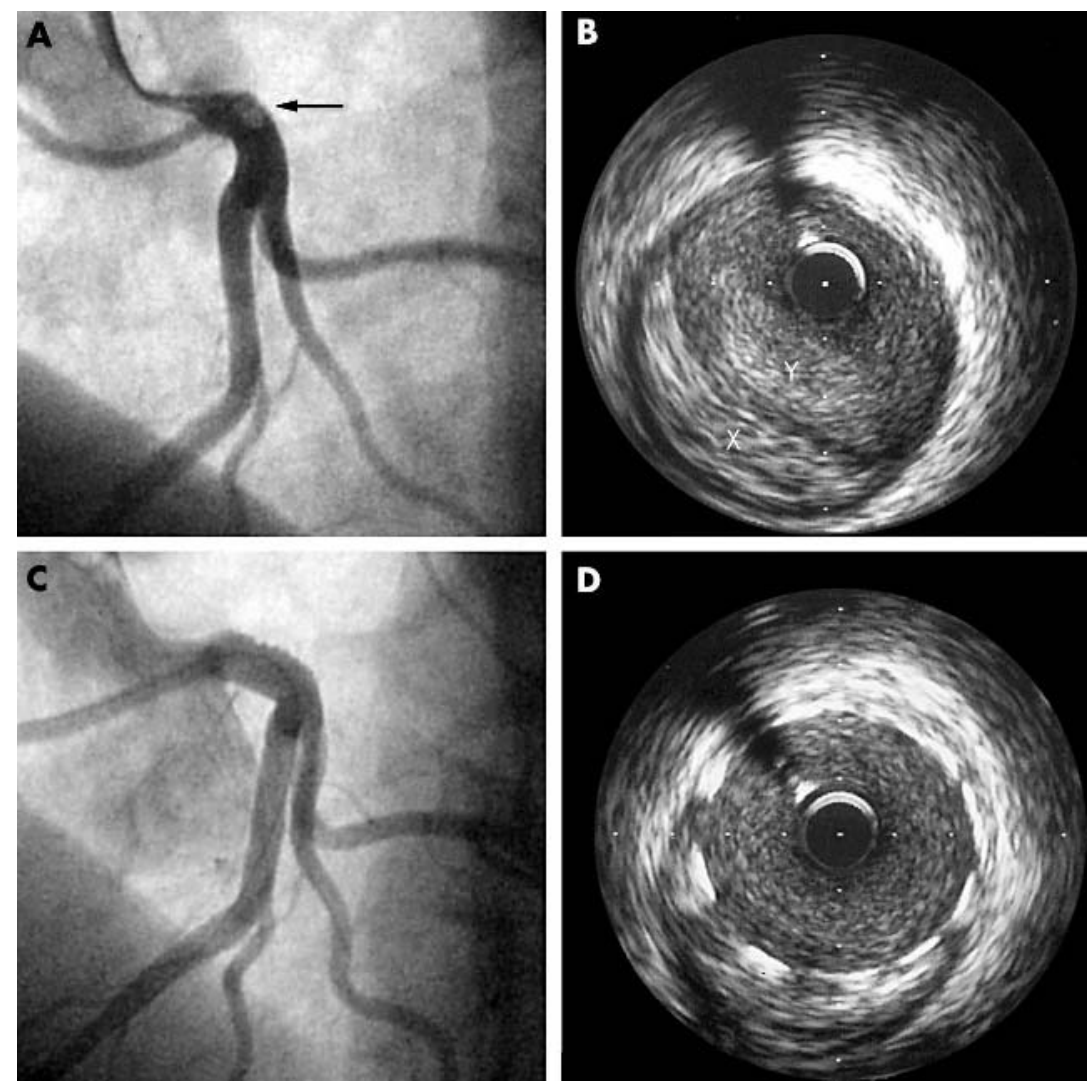